Para enlazar con este artículo / To link to this article:

http://dx.doi.org/10.14198/fem.2019.33.05

Para citar este artículo / To cite this article:

Dunezat, Xavier. «Las luchas de sin-papeles: entre comunidad prescrita, dispersión real y profundización democrática». En Feminismo/s, 33 (junio 2019): 117-144. Dosier monográfico: Diálogos entre la democracia participativa y la interseccionalidad. Construyendo marcos para la justicia social, coords. Patricia Martínez-García y Jone Martínez-Palacios, DOI: 10.14198/fem.2019.33.05

\title{
LAS LUCHAS DE SIN-PAPELES: ENTRE COMUNIDAD PRESCRITA, DISPERSIÓN REAL Y PROFUNDIZACIÓN DEMOCRÁTICA
}

\author{
UNDOCUMENTED PEOPLE STRUGGLES: \\ BETWEEN PRESCRIBED COMMUNITY, ACTUAL \\ DISPERSION AND DEMOCRATIC DEEPENING
}

\begin{abstract}
Xavier DUNEZAT
Centro de Investigaciones Sociológicas y Políticas de Paris (CRESPPA) y Unidad de Investigaciones Migraciones y Sociedad (URMIS)

dunezat.xavier@wanadoo.fr https://orcid.org/0000-0002-4554-4744
\end{abstract}

\section{Resumen}

Privilegiando el marco del pensamiento feminista negro de Patricia Hill Collins, el artículo analiza varias dimensiones del estatuto y de la dispersión de los/as sin-papeles en relación con la dinámica interseccional de los ejes de opresión. Los/as sin-papeles constituyen una «comunidad sobre el papel». Por eso la experiencia militante colectiva es muy importante como condición previa de grupo movilizado. Sin embargo, dentro de dos luchas diferentes de sin-papeles en Francia, centenares de observaciones muestran que la matriz militante se vuelve ambivalente. Por un lado, porque al incorporarse a formas disponibles de militancia dirigidas por sus aliados/as (coerción, autonomía, negación), los/as sin-papeles se enfrentan a un proceso de desposesión en cuanto a la dirección de sus luchas. Por otro, los fracasos no deben esconder la emergencia de comunidades reales de militancia dentro de las cuales se cristalizan varias dinámicas de profundización democrática en los ámbitos ideológicos, prácticos y éticos.

Palabras clave: sin-papeles, militancia, interseccionalidad, feminismo negro.

Los contenidos de la revista se publican bajo una licencia de Creative Commons Reconocimiento 4.0 Internacional (CC BY 4.0)

Feminismo/s 33, junio 2019, pp. 117-144 


\begin{abstract}
By focusing on the framework of Patricia Hill Collins' black feminism thought, the article analyzes the various dimensions of the status and dispersion of undocumented people, related to the intersectional dynamic of the systems of oppression. The undocumented people constitute a community «on paper». For this, the collective activist experience is very important as a precondition for a mobilized group. However, as hundreds of observations show, within two struggles of undocumented people in France, the activist matrix becomes ambivalent. On the one hand, by joining available forms of activism led by its allies (coercion, autonomy, negation), undocumented people face a process of dispossession as to the direction of their struggles. On the other hand, failures should not hide the emergence of real communities of activism within which diverse dynamics of democratic deepening crystallize in the ideological, practical and ethical domains.
\end{abstract}

Keywords: Undocumented people, activism, intersectionality, black feminism.

\title{
1. INTRODUCCIÓN ${ }^{1}$
}

El presente artículo trata el movimiento de sin-papeles a través de dos dinámicas locales: un «colectivo de apoyo a las personas sin-papeles» (Colectivo) y un «comité de los sin-papeles» (Comité2), en Francia. Tienen en común el objetivo de construir un «movimiento con los pobres» y no «para los pobres» (Péchu) pero los/as sin-papeles aparecen más como una «comunidad prescrita» por los/as aliados/as que movilizada. En realidad, nunca consiguió constituirse esta de manera duradera y masiva, tanto a nivel local como a nivel nacional. Las experiencias son precarias, minoritarias y poco representativas de la diversidad de los/as sin-papeles. Por eso, hablamos de «dispersión real». Sin embargo, las luchas estudiadas no se pueden reducir a experiencias de fracaso porque consiguen durar y los/as participantes no dejan de expresar su compromiso con los principios de la lucha y el hecho de luchar.

Desde el marco del «feminismo materialista» (Delphy 121-164), de la consustancialidad de los rapports sociaux (Kergoat 125-140; Galerand y

1. Agradezco a mis compañeras feministas Chiqui y Eva la revisión castellana de este artículo.

2. Cuya localización exacta no se indicará para evitar que los resultados de este trabajo sean empleados para deslegitimar la acción de estos movimientos.

Feminismo/s 33, junio 2019, pp. 117-144 
Kergoat, intersectionnalité; Cahiers du Genre) y del "paradigma feminista materialista de la interseccionalidad» (Juteau 129), propongo aquí discutir la noción flexible y dinámica de «comunidad» como salida propuesta por Patricia Hill Collins (Difference 27-28), analizando, por un lado, los procesos por los cuales la comunidad de los/as sin-papeles aparece más como una comunidad «sobre el papel» que «movilizada» adaptando la distinción de Bourdieu entre «clase sobre el papel»y «clase movilizada» (4-5); por otro, cómo la lucha de los/as sin-papeles en sí misma se vuelve una experiencia política emancipadora para la gente que participa y se acerca a una forma de profundización democrática.

Usaré los resultados de una observación participante ${ }^{3}$ desde finales de los años 1990 (Dunezat, Dominación 402-405). En efecto, mientras que se suspendía mi militancia en colectivos feministas y mi inmersión en movimientos de parados/as (Cohen y Dunezat 318-323), mi trayectoria militante se transforma gracias a la invitación de la madre de una alumna para formar parte de una permanencia jurídica de ayuda a los/as sin-papeles. Desde el principio de mis investigaciones sobre los movimientos a favor de grupos excluidos, me centré en la división del trabajo militante por la cual los ejes de opresión de sexo, clase y raza se entrelazan para dinamizar un orden militante desigual y jerarquizado. En este artículo, entenderé que esta división del trabajo militante es un mecanismo contextual para centrarme en los «factores sistémicos, institucionales y experienciales» (Martínez-Palacios y Martínez-García, Justicia 11) de la dialéctica entre dominación y resistencia.

Específicamente, quiero poner de relieve que el fracaso sistémico de las luchas por el cambio institucional de la condición de sin-papeles proviene, a la vez, de las dinámicas interseccionales que producen tal condición, de la posición dominante de los/as aliados/as dentro de estas luchas y de su incapacidad para tener en cuenta las luchas reales de los/as sin-papeles en sus dimensiones individuales y comunitarias. Lo acontecido con la «comunidad negra» conformándose en una «variedad de instituciones, de redes, de

3. El uso complementario de la entrevista en profundidad y del cuestionario aparecerá poco aquí. Son centenares de observaciones. Por una parte, fueron redactadas durante el momento militante (Comité). Por otra, combino los productos del trabajo militante de actas y de permanencia jurídica con informes elaborados a partir de mi experiencia continuada (Colectivo). 
comunicación y de prácticas sociales que ayudan a los/as afro-americanos/as para reaccionar a los desafíos sociales, económicos, políticos que afrontan» (Collins, Pensée 439) no sucede con la «comunidad sin-papeles». Esta no logra conformarse en marco práctico, cognitivo, emocional de la resistencia (Collins, Difference 27-28).

En la primera parte del artículo, defiendo una sociología relacional de las luchas de sin-papeles. En la segunda parte, planteo cómo el pensamiento feminista negro permite analizar varias dimensiones contradictorias de la experiencia de los/as sin-papeles: por un lado, la producción de un estatuto identificable y analizable en términos de opresión específica; por otro, las formas de dispersión de los/as sin-papeles, relacionadas con su heterogeneidad de origen y la dinámica interseccional de los ejes de opresión. En la tercera parte, muestro que la acción colectiva no puede estimular una «comunidad sin-papeles» porque, dentro de las formas disponibles de militancia animadas por los/as aliados/as, los/as sin-papeles se enfrentan a un proceso de desposesión de sus luchas y de negación de sus experiencias comunitarias reales, en gran parte desconectadas del estatuto de sin-papeles. En la cuarta parte, pongo de relieve que los fracasos no deben esconder el hecho de que las luchas pueden producir comunidades reales de militancia, dentro de las cuales, se cristalizan varias dinámicas de profundización democrática en los ámbitos ideológicos, prácticos y éticos.

Finalmente, si el estatuto de sin-papeles actúa como un marco experiencial dentro del cual los/as individuos/as se conectan con las instituciones opresivas de la política migratoria, éste no constituye un marco colectivo ya sea práctico, cognitivo o emocional dentro del cual las respuestas políticas están construidas por los/as sin-papeles. En este sentido, conforman una comunidad sobre el papel porque está más prescrita por los/as aliados/as y no es comparable con la comunidad movilizada de las mujeres negras tal como la presenta Collins. Por eso la experiencia militante colectiva, en el sentido aquí de «luchas por el cambio institucional» (Collins, Pensée 319), es una condición previa de una clase movilizada aunque la matriz militante de la experiencia de sin-papeles se vuelve ambivalente, entre opresión y emancipación. 


\section{UN ANÁLISIS DE LAS LUCHAS DE SIN-PAPELES BAJO EL PRISMA RELACIONAL}

El paradigma interseccional, entre otros, me ha ayudado a situar mi punto de vista (2.1) y es un eje de análisis crítico de la sociología de las luchas de sin-papeles (2.2), enriqueciendo un enfoque relacional (2.3).

\subsection{Un punto de vista militante}

Ya sea por los dispositivos democráticos «por invitación» o por los movimientos sociales «por abajo», la mirada crítica feminista en sentido amplio fue innovadora por su «atención especial a la inclusión» (Martínez-Palacios y Martínez-García, Miradas 346) y a las dinámicas reales en términos de transparencia o de proceso de decisión. La preocupación científica desborda aquí la indagación porque interseccionalidad y profundización democrática «se conciben fundamentalmente como marcos de trabajo para reflexionar y practicar la justicia social» (Martínez-Palacios y Martínez-García, Justicia 12). En el cumplimiento de esta última, defiende Collins una epistemología feminista negra que tenga «una base existencial, material» (391) y que no sea ciega o sorda a varias dimensiones negadas por el positivismo y el dogma de la neutralidad axiológica; es decir, la experiencia como criterio de significación, el uso del diálogo como modo de evaluación, la ética de la responsabilidad personal y del care, lo que se refiere específicamente a la importancia de las emociones en el diálogo y a la capacidad de empatía en el enfoque científico (383-411).

Aunque yo, en mi militancia, pueda «reproducir la dominación «del que más grita», que es a menudo un hombre blanco, de clase media, con estudios universitarios y una amplia red de contactos» (Martínez-Palacios y MartínezGarcía, Miradas 347), mi trabajo académico no renuncia a contribuir al reto de la justicia social. Primero, mis terrenos -los movimientos sociales- se confunden con mis experiencias de militancia y mi eje de investigación -la división del trabajo militante desde un marco feminista- guía mi atención por el tema de la inclusividad dentro de las luchas. Segundo, mi militancia en apoyo a grupos excluidos me ha posicionado conformando un punto de vista que rechaza varias teorías sociológicas, las cuales condenan a las personas que son del orden social más bajo a la apatía. Específicamente, defiendo -con 
otros/as- la presunción de movilización de los/as dominados/as cuando tales teorías (solo) usan «definiciones dominantes de la militancia política y de la resistencia» que niegan el empoderamiento procedente de «las luchas por la supervivencia colectiva», de «las esferas informales, privadas y en apariencia invisibles de la vida social» (Collins, Pensée 316-317). Tercero, me inscribo en la agenda científica que interconecta dominación y resistencia en la sociología de los grupos dominados (Kergoat; Collins) a través de «la premisa de que las vivencias de opresión no agotan las posibilidades de resistencia» (Martínez-Palacios y Martínez-García, Miradas 348). El «empoderamiento» puede proceder de las esferas biográficas y comunitarias (Martínez-García 391-393; Jabardo Velasco 381-382), una inserción militante visible de las «prácticas de subsistencia» (Cohen y Dunezat 135-144).

\subsection{Dinámicas de la sociología de las luchas de sin-papeles}

Se suele considerar que las luchas de sin-papeles como luchas colectivas y públicas, enfrentándose con el sistema institucional y criticando a la extranjerización y la ilegalización que producen las leyes de inmigración (Varela Huerta, Derecho) aparecieron en los años setenta en Francia (Simeant) y tuvieron mucha fuerza en los años noventa, antes de exportarse a España (Krueger), primero en la región de Murcia (Pedreño y Hernández) y después en otras comunidades. «Tomando el caso francés como paradigmático» (Santi Pereyra) y el caso español como «reflejos» (Krueger) que suscitaron numerosas contribuciones académicas, la acción colectiva de los/as sin-papeles se encuentra en la intersección de tres ideas.

La primera se refiere al hecho de que, por fin, luchas autónomas de sin-papeles han surgido y que «las luchas protagonizadas por migrantes son un novísimo tipo de movimiento social que nos muestran nuevas formas de performar la protesta social» (Varela Huerta, Luchas 147). Destacan aquí los estudios que valorizan la importancia de «la irrupción» (Aierbe) de estos nuevos «sujetos políticos» dentro del proceso de «la disputa cotidiana de construcción del sujeto inmigrante frente al Estado» (Santi Pereyra). Se analizan tales luchas como una nueva forma de «subjetivación» (Le Borgne 183), de «extensión de la ciudadanía» (Suárez Navaz et al.), incluso «una nueva idea de la ciudadanía» (Krueger), caracterizada por la reivindicación 
del derecho a tener derechos (Suárez Navaz et al.) y por la disidencia transnacional (Varela Huerta, Luchas) aunque indisociable de un proceso nacional de construcción sociopolítica de la falta de documentos como marca de la irregularidad (Jaegermann). Con estas luchas, se puede percibir una «sublimación de las asignaciones identitarias» (Le Borgne 185), como las de «clandestino» o «irregular».

La segunda idea intenta poner de manifiesto que las luchas de sin-papeles participan de varias luchas de grupos excluidos que se analizaron como una renovación de los movimientos sociales, lo que desembocó en la expresión francesa de «movimientos de sin» (designando movimientos de sin-papeles, sin-empleo, sin-hogar...). Al respecto, destaca el enfoque teórico francés de inspiración norteamericana con la corriente de «las movilizaciones de los recursos» el cual caracterizó tales movimientos como «movilizaciones improbables» (Simeant; Mathieu) porque los grupos excluidos son tan carentes de recursos (económicos, culturales, militantes, sociales...) que no pueden movilizarse sin el apoyo de organizaciones y alianzas, específicamente con militantes o figuras sociales capaces de remediar la falta de recursos. Estas movilizaciones se han caracterizado por su «heterogeneidad constitutiva»y su dimensión «heterónoma» (Mathieu) porque suponen la coexistencia de «los beneficiarios de la acción colectiva» y de los «militantes por conciencia» (Mc Carthy y Zald). Por su centralidad en la formación de la acción colectiva, estos trabajos fueron más discretos sobre la heterogeneidad de los/ as beneficiarios/as (de sexo, raza entre otras) y sobre las relaciones de poder entre «militantes»y «beneficiarios», así como sobre la producción dialéctica de estos dos grupos (entre otros) dentro de la lucha mediante la división del trabajo militante (Cohen y Dunezat 40-44).

Esto nos lleva a las aportaciones de la reflexión feminista en sentido amplio: primero, las de la sociología del género -de los rapports sociaux de sexe en el ámbito francés (Kergoat)- sobre los movimientos sociales como dinámicas permeables a la dominación masculina y a los conflictos de género (Fillieule y Roux); segundo, las del paradigma de la interseccionalidad de los sistemas de opresión -de su consustancialidad-sobre el proceso completo de formación de la acción colectiva y de sus contradicciones. Por el tema de las luchas de sin-papeles, destacan aquí los pocos estudios que han percibido la centralidad de las relaciones ambivalentes, hecha de alianza y de asimetría de 
poder, entre los/as aliados/as y los/as sin-papeles (Royo et al.; Varela Huerta, Luchas). Pero, al revés de un enfoque monista de la dominación, la centralidad en tal distinción no debe descuidar cómo otras distinciones atraviesan la acción colectiva y cómo la misma distinción se encuentra co-formada (Falquet) por varios rapports sociaux y al menos los de sexo, raza y clase.

También en la acción colectiva «diferentes sistemas de opresión se interconectan e intersectan, interactúan y se imbrican en diferentes realidades sociales y materiales» (Royo et al. 225). Por eso, hace falta que «el enfoque cualitativo e interseccional de la investigación» dentro de los movimientos sociales se fije al menos como doble objetivo el «reemplazar las categorías sociales por procesos sociales» y el «tomar las relaciones sociales como la principal unidad de análisis», combinando las dinámicas de asimetría y las de alianza (Royo et al. 240). Aunque mi marco teórico se nutra de la sociología francesa de los rapports sociaux, la mayor parte de mi propio trabajo participa de estas dinámicas feministas transnacionales que van a actuar aquí como un telón de fondo de mi análisis.

\subsection{El prisma relacional: aliados/as y sin-papeles}

Entre otras, destaca la propuesta metodológica de interrogar la dinámica de la consustancialidad de los rapports sociaux partiendo, sobre el terreno, de las categorías y/o de los disensos que estructuran de manera privilegiada las interacciones (Dunezat, Herramientas 103-105; Cohen y Dunezat 103-108), es decir las que están explícitamente subjetivadas, para analizar, después, cómo encarnan las dinámicas entrelazadas de sexo, clase y raza. Por ejemplo, en las luchas de sin-papeles, dos sistemas de categorización coexisten: lo más subjetivado proviene de la distinción entre «aliados» y «sin-papeles/migrantes»; el otro, también muy subjetivado, proviene de la distinción entre «hombres»y «mujeres». Aunque otros ejes de opresión (clase, edad, sexualidad...) estructuran las interacciones, decidí empezar la etnografía de las luchas de sin-papeles centrándome en la distinción entre aliados/as y sin-papeles/migrantes (tabla 1). 
Las luchas de sin-papeles: entre comunidad prescrita, dispersión real y profundización democrática

Tabla 1. Presentación de los movimientos estudiados

\begin{tabular}{|c|c|c|}
\hline & Colectivo & Comité \\
\hline Localización y población & Oeste (250.000) & Norte (1.000.000) \\
\hline $\begin{array}{l}\text { Número local de sin- } \\
\text { papeles }\end{array}$ & $\begin{array}{l}\text { Decenas (inicialmente) } \\
\text { Centenares (actualmente) }\end{array}$ & Miles \\
\hline Duración del movimiento & $12 / 2001-2019$ & 09/1996-2019 \\
\hline Período de inmersión & $\begin{array}{c}12 / 2001-2019 \\
\text { (excepto 2006-2007) }\end{array}$ & 09/2006-07/2007 \\
\hline $\begin{array}{l}\text { Número de participantes } \\
\text { (asambleas generales) }\end{array}$ & $\begin{array}{c}20-40 \\
\text { (estable) }\end{array}$ & $\begin{array}{l}100-300 \\
\text { (instable) }\end{array}$ \\
\hline Registros de acción & \multicolumn{2}{|c|}{$\begin{array}{c}\text { Ocupaciones, concentraciones, manifestaciones, } \\
\text { octavillas }\end{array}$} \\
\hline Registro privilegiado & Ocupación & Huelga de hambre \\
\hline $\begin{array}{l}\text { Número de casos } \\
\text { atendidos } \\
\text { (permanencia jurídica) }\end{array}$ & $\begin{array}{c}1500 \\
(1997-2018)\end{array}$ & $\begin{array}{c}5000 \\
(1996-2007)\end{array}$ \\
\hline $\begin{array}{l}\text { Sin-papeles } \\
\text { (en \%) }\end{array}$ & $\begin{array}{l}<20-30 \% \\
\text { (instable) }\end{array}$ & $\begin{array}{c}>90 \% \\
\text { (estable) }\end{array}$ \\
\hline $\begin{array}{l}\text { Hombres } \\
\text { (en \%) }\end{array}$ & $\begin{array}{l}\text { 30\% (inicialmente) } \\
50 \% \text { (actualmente) }\end{array}$ & $>80 \%$ \\
\hline $\begin{array}{l}\text { Mujeres } \\
(\text { en } \%)\end{array}$ & $\begin{array}{l}\text { 80\% (aliados/as) } \\
30 \% \text { (sin-papeles) }\end{array}$ & $\begin{array}{l}10 \% \text { (aliados/as) } \\
20 \% \text { (sin-papeles) }\end{array}$ \\
\hline $\begin{array}{l}\text { Zona geográfica de origen } \\
\text { (sin-papeles) }\end{array}$ & $\begin{array}{l}\text { Árabe (inicialmente) } \\
\text { África (actualmente) }\end{array}$ & $\begin{array}{c}\text { Árabe }=\text { África } \\
(\text { Asia })\end{array}$ \\
\hline $\begin{array}{l}\text { Reclutamiento professional } \\
\text { (Aliados/as) }\end{array}$ & $\begin{array}{c}\text { Profesores/as } \\
+ \text { personal superior } \\
+ \text { estudiantes + precarios/as } \\
+ \text { pensionistas (de la } \\
\text { enseñanza) }\end{array}$ & $\begin{array}{l}\text { Profesores/as> } \\
+ \text { empleados/as } \\
+ \text { inactividad }\end{array}$ \\
\hline
\end{tabular}

Fuente: Elaboración propia

La permanencia jurídica del Oeste a la cual me uní en el año 1998 ayudaba en esta época a menos de diez casos y el número siempre creció. Cada lunes, participo en la acogida de personas extranjeras que tienen dificultad o ya no tienen posibilidad legal de regularizar su situación. A partir del año 2000 somos cuatro militantes blancos/as, dos hombres y dos mujeres de trayectoria 
libertaria y feminista entre los/as cuales hay tres profesores para proponer ocupaciones de edificios públicos y pedir soluciones colectivas. A pesar de los fracasos, matizados por el sentimiento de que los/as sin-papeles apoyados no eran deportados, nos invitaron varios militantes blancos de trayectoria libertaria a crear, a finales de 2001, un «Colectivo de apoyo a las personas sin-papeles» para complementar la permanencia jurídica. Este Colectivo no consiguió desarrollarse hasta que, en abril de 2002, Jean-Marie Le Pen, líder de la extrema derecha electoral, llegase a la segunda ronda de las elecciones presidenciales francesas.

Aprovechando el movimiento ciudadano entre las dos rondas e invitándolo para apoyar la liberación de un sin-papeles en detención, el Colectivo se agrupó y, desde esta época, se reúnen entre 20 y 40 personas cada martes en un edificio asociativo del centro de la ciudad, organizando acciones según lo que la permanencia jurídica considera relevante en cuanto a los trámites de los/ as sin-papeles. Desde 2002, participo en estas dos estructuras y, desde 2007, tengo una posición central porque me convertí en el último superviviente del grupo iniciador y en una especie de garante del funcionamiento original.

Además, en el año 2006-2007, por razones profesionales, tuve que mudarme a otra ciudad del Norte y me uní a un «Comité de los sin-papeles» que ya existía desde el año 1996. Éste fue creado en el contexto del movimiento nacional de sin-papeles del mismo año. Por lo que me contaron sus protagonistas durante entrevistas, el Comité fue iniciado durante una huelga de hambre, cuando unos sin-papeles pidieron el apoyo de militantes árabes y negros de nacionalidad francesa, de trayectoria política y sindical comunista, entre los cuales había tres profesores. En comparación con el Colectivo, destaca el Comité por su fama nacional numérica y política por los éxitos de sus huelgas de hambre y su funcionamiento jerarquizado que me ha sorprendido mucho.

\section{LA COMUNIDAD Y LA DISPERSIÓN DE LOS/AS SIN-PAPELES}

El pensamiento feminista negro, tal como lo describe Collins, es un modelo heurístico para analizar la dialéctica de la opresión y de la militancia de muchos grupos oprimidos, específicamente cuando se define como un «marco de análisis de la diáspora» construido mediante las experiencias de 
la esclavitud, del colonialismo, del imperialismo, de las migraciones (Pensée 75). En efecto, combina un análisis sobre las condiciones compartidas de las mujeres afrodescendientes por su «plaza distinta dentro del contexto transnacional global caracterizado por el apartheid de género mundializado» (Pensée 382) y unas precauciones sobre la diversidad real de sus experiencias según la clase, la sexualidad, la nacionalidad...

Este pensamiento nos ofrece un punto de vista peculiar para describir a los/as sin-papeles como un estatuto identificable (3.1). Sin embargo, nos permite también tener en cuenta sus contradicciones constitutivas y objetivar su realidad de «comunidad sobre el papel» (3.2).

\subsection{La matriz de la dominación del estatuto de sin-papeles}

Si el consenso es fuerte en cuanto a la definición, según la cual «los sin-papeles son las personas extranjeras que no tienen el título de residencia exigido por la ley del país en el que se encuentran» (Krueger), se notan disensos en cuanto a las situaciones jurídicas reales que abarca la categoría. Dentro de los movimientos estudiados, se considera que los/as sin-papeles son las personas extranjeras que no tienen el título de residencia de diez años renovable automáticamente, cualquiera que sea el motivo de expedición (político u otro).

La posición social de sin-papeles se ajusta a la definición de la opresión caracterizando «toda situación injusta dentro de la cual, sistemáticamente y durante un largo período, un grupo niega a otro el acceso a los recursos sociales» (Collins, Pensée 39). En un país, la nacionalidad y los papeles pueden ser usados para privar de derecho a los derechos (empleo, instalación, servicios sociales, ciudadanía, etc.) o precarizarlos (circulación, escuela, alojamiento, sanidad...), incluso para encerrar a una persona con policía y esposas antes de deportar. La opresión de los/as sin-papeles tiene un origen «estructural» porque es el producto de «las políticas y las normas del sistema legal» (Collins, Pensée 418), materializadas por una ley migratoria (en Francia, el Código de entrada y residencia de los extranjeros y del derecho de asilo).

Pero si la ley define las categorías de residencia y las condiciones para acceder a éstas, la condición de sin-papeles se experimenta mientras tiene lugar la relación concreta con varias instituciones encargadas de la gestión de la inmigración, entre las cuales destacan las prefecturas de cada departamento. 
«El ámbito disciplinario del poder» designa así «el modo de regulación que se basa en las jerarquías burocráticas y las técnicas de vigilancia» y que busca crear poblaciones «tranquilas, pulidas, obedientes y disciplinadas» (Collins, Pensée 423-424). Específicamente, la probabilidad de alcanzar un derecho de residencia depende no sólo de la ley sino de la aceptación de las prácticas prefectorales de vigilancia cuando la persona extranjera se ve obligada a facilitar las huellas dactilares, a presentar documentos, dirección, etc. El nivel disciplinario aparece como un medio muy eficaz cuando el poder quiere combinar el cumplimiento de sus obligaciones internacionales (respetar el derecho a la vida familiar, a la protección política...) con la producción de normas, más o menos legales, para impedir, desanimar o frenar el acceso a la residencia.

El estatuto de sin-papeles abarca «tres dimensiones interdependientes» que funcionan como «un sistema de alta eficacidad de control social» con el objetivo de acantonamiento en «una plaza asignada y subordinada» (Collins, Pensée 40). Primero, a nivel económico, la prohibición del empleo condena a los/as sin-papeles a varias experiencias de supervivencia que se devuelve en actividad a tiempo completo: la sobreexplotación de su trabajo asalariado escondido y/o la búsqueda de ayudas ante varias autoridades y asociaciones. Se puede añadir aquí la movilización de recursos, materiales e intelectuales, provocada por todos los trámites administrativos, sobre todo cuando las colas de espera, la virtualización obligatoria, los largos plazos, la falta de personal y la violación asumida de los principios del servicio público se han transformado en un modo rutinario de la administración migratoria (Migrations Société 91-107). Segundo, a nivel político, los/as sin-papeles se encuentran privados de los derechos y de las libertades que definen la ciudadanía dentro de las democracias representativas mientras que su acceso a cualquiera forma de participación política se vea condicionado por sus prácticas de subsistencia, su falta de disponibilidad y su miedo a los riesgos asociados a la salida a la calle.

Tercero, a nivel ideológico, los/as sin-papeles deben enfrentarse con «el ámbito hegemónico del poder», es decir, una serie de «atributos presuntos» que «sirven para justificar la opresión» (Collins, Pensée 40), entre los cuales se encuentra la presunción sistemática de la «migración económica»con todo el conjunto de estereotipos contradictorios que conlleva (como quitar el trabajo de los/as nativos/as, buscar ayudas sociales y ser vago), cuando no 
es la presunción del «terrorismo»y del «islamismo radical». El atributo de «invasor» es sin duda lo más difícil de soportar cuando el papel es la única (pequeña) diferencia que justifica un tratamiento (tan) diferente en cuanto a la posibilidad de una subjetivación territorial, lo que revela el lema de resistencia de los/as huelguistas sin-papeles parisinos a finales de los años 2000: «Vivimos aquí, trabajamos aquí, nos quedamos aquí».

\subsection{Las matrices de la dispersión real de los/as sin-papeles}

Sin embargo, la comunidad de los/as sin-papeles, a pesar de que su estatuto la convierte en identificable, se caracteriza por una gran dispersión real. Se combinan aquí varias matrices privilegiando el modo de análisis de Collins.

Primero, a «nivel interpersonal» o «experiencial del poder» (Collins, Difference 26), los/as sin-papeles comparten con los/as migrantes y los/as franceses la constatación de que «a cada individuo se le asignan cantidades variables de discapacidad y de privilegio por los múltiples sistemas de opresión que rigen su vida» (Collins, Pensée 433). En el caso de los dos movimientos estudiados y usando aquí un enfoque más aditivo, la heterogeneidad de sexo y de origen (tabla 1) -también de procedencia social, edad, sexualidad, nacionalidad, ...- es muy relevante. Respecto a la interseccionalidad, tres dinámicas son importantes aquí. No es tan determinante el origen geográfico como el tipo de lazos que tiene el país de procedencia y él de acogida. La conciencia común de la diáspora no debe esconder que la participación militante es más frecuente y asumida por parte de la gente que subjetiva su derecho a los papeles por las responsabilidades históricas, esclavistas y coloniales, de Francia en la situación actual de su país (Le Borgne). La segunda dinámica se refiere a los lazos que han tenido los/as sin-papeles de varias nacionalidades antes de su llegada. Por ejemplo, los conflictos entre árabes y africanos/as que los/as aliados/as esencializan muchas veces como «tensiones comunitarias» esconden el hecho de que muchos/as africanos/as se enfrentaron, durante su migración, a un racismo violento en Marruecos y consideran a los/as árabes como blancos/as.

También sería necesario que nuestro estudio tomase en consideración la diversidad de las experiencias de las mujeres sin-papeles en cuanto al «trabajo maternal» (Collins, Pensée 326). Por ejemplo, se priorizan en las luchas las 
situaciones familiares con niños, a expensas de la gente soltera. Sin embargo, en el caso de muchas mujeres negras que llegan a Francia sin sus niños, las consideramos con los esquemas racistas del abandono cuando su estrategia de migración se inserta en una red de actividades y de experiencias características de la opresión y de la resistencia de las mujeres negras, específicamente la organización colectiva del trabajo maternal mediante las «madres supletorias» (Collins, Pensée 285), encargadas de cuidar a los niños durante la migración pionera de la madre.

Segundo, las políticas migratorias mezclan dinámicas de separación y de jerarquización en el tratamiento de la población migrante extranjera, lo que desemboca en la hipótesis del «racismo institucional» (Carmichaël y Hamilton 38-40) consustancial a tales políticas. A nivel estructural, para abrir las fronteras, la construcción europea estableció un orden migratorio dentro del cual se superponen invasión fantasma y migrantes extracomunitarios, entre los/as cuales árabes y africanos/as tienen el liderazgo mientras que la inmigración europea represente la mitad de las entradas reales (Cornuau y Dunezat 470-475). Por un lado, desde 2004, los/as nacionales de los países «comunitarios» no necesitan permiso de residencia para instalarse en Francia. Por otro, la inmigración legal se encuentra registrada anualmente desde 2003 mediante la emisión de permisos de residencia, dentro de los cuales árabes y africanos/as son sobrerrepresentados. Tales modificaciones legales han desembocado en subjetivaciones múltiples dentro de la población que tiene en común la migración porque ocurre que «la categoría de «blanco» es alargada» para que grupos antes víctimas de racismo institucional se encuentren «clasificados «blancos»» (Collins, Pensée 430). Y, en el ámbito hegemónico del poder racista francés, cuando eres blanco/a, no puedes ser migrante porque no eres árabe o negro/a. Tal dinámica ha cortado los nexos entre los/as sin-papeles y una parte de la población migrante real.

Otra dimensión importante es el hecho de que las experiencias individuales del estatuto de sin-papeles y las subjetivaciones son múltiples porque, a nivel disciplinario, el racismo institucional hace distinciones según las posiciones en otros ejes de opresión. Por ejemplo, el trabajo maternal, sobre todo la maternidad de niños franceses, aparece como una de las vías eficaces para tener más derechos. No se trata aquí de favoritismo sino de imbricación entre el racismo y el patriarcado porque, en relación con «las luchas por la 
supervivencia colectiva», una de las «estrategias para socavar las instituciones opresivas» (Collins, Pensée 326) del racismo institucional es la de tener niños.

Es necesario ahora que se precise lo que ocurre cuando la gente sin-papeles, a nivel experiencial, entra en contacto con otra matriz: la militancia.

\section{FORMAS MILITANTES DISPONIBLES: COERCIÓN, AUTONOMÍA, NEGACIÓN}

Los/as sin-papeles entran, por razones de supervivencia, en contacto con el mundo de la militancia en manos de franceses, quienes por su abrumadora mayoría, son blancos/as ${ }^{4}$, de clase media y no experimentaron la migración. Considerando aquí la dominación masculina en la división del trabajo militante como un telón de fondo (Dunezat, Dominación 405-411), se puede experimentar dos formas de militancia el modelo de la coerción (4.1) y él de la autonomía (4.2) que tienen una consecuencia común: la desposesión real de los/as sin-papeles en cuanto al control de las luchas por el cambio institucional. Específicamente, los/as aliados/as no consiguen construir puentes entre las luchas reales de los/as sin-papeles, es decir las luchas de «las esferas informales, privadas y en apariencia invisibles», y la militancia dominante en el sentido de «actividad política dentro de las esferas públicas, oficiales y visibles» (Collins, Pensée 316) (4.3).

\subsection{El Comité y el modelo de la coerción}

Al llegar al Comité del Norte, con su estatuto legal de asociación, descubrí un movimiento muy jerarquizado y vinculante. Me ofrecí para participar en la permanencia jurídica y aprendí que los/as acogedores eran sólo aliados/ as porque el trabajo jurídico era prohibido a los/as sin-papeles por riesgo de «favoritismo». Después de dos meses y una vez aceptado por el Comité mi proyecto para investigar, me facilitaron el acceso a todos los datos, salvo los de la dirección política y de los grupos de sin-papeles. Me enteré así de que la estructura formal era muy jerarquizada, con funciones estrictamente definidas. Las decisiones requerían un portavoz, miembro de una dirección

4. Blancos y Negros son construcciones políticas del racismo. No son «identidades de color». 
política de tres hombres (aliados), y un «bureau» ${ }^{5}$ semanal compuesta por treinta personas, procedentes de la dirección política que presidía las reuniones, de los grupos de sin-papeles y de varios/as invitados/as (como yo).

Los/as centenares de sin-papeles se encontraban repartidos entre siete grupos de sin-papeles (seis de hombres y uno de mujeres). Cada grupo tenía dos jefes elegidos por la dirección política y éstos/as tenían que participar en el «bureau», por supuesto, poco feminizado. El nivel prescrito de legitimación era la asamblea general semanal de los/as sin-papeles, la cual consistía en escuchar un largo discurso inaugural del portavoz, escuchar las actas de las acciones por los/as jefes de cada grupo de sin-papeles, escuchar las noticias sobre los/as sin-papeles detenidos ${ }^{6}$ y aprobar, con un sistema de voto mayoritario, las directrices propuestas por la dirección política. Destacaba así el hecho de que la toma de la palabra no era libre y sólo dependía del arbitrio de la dirección política.

En efecto, desde el primer día, noté la centralidad del portavoz -un hombre negro, profesor, de 50 años- porque, a veces, se le esperaba hasta una hora antes de empezar la manifestación. Durante veinte minutos, tomaba la palabra en el centro de la plaza de la República de la ciudad para comentar la actualidad y, tras aplausos, nos íbamos a manifestar durante una hora. Los/as sin-papeles tenían que gritar, cantar, tocar música y, cuando no era suficiente, el portavoz les recordaba la obligación de manifestar con ruido su indignación para «sacar los papeles». Por lo que se refiere a las octavillas y a las acciones, estaban decididas y preparadas por la dirección política -el portavoz en la mayoría de los casos-, después discutidas en el «bureau»y algunas veces legitimadas por la asamblea. El nivel de reparto del trabajo tenía lugar en el «bureau» y lo realizaban los grupos de sin-papeles. En términos de acciones, el Comité combinaba lo que llamaba luchas de baja intensidad (manifestación semanal desde 1996), de media intensidad (ocupaciones) y de alta intensidad (huelga de hambre hasta regularización).

5. Es un nivel intermedio de decisión entre la dirección y la asamblea.

6. Una mujer árabe francesa tenía responsabilidad de registrar las personas detenidas, obtener datos para saber si eran verdaderos/as militantes o «luchadores del domingo», visitarlos en detención y llevarles vestidos... 
Todo el funcionamiento estaba pensado para agrupar y preparar a los/ as sin-papeles hasta que estaban listos para empezar la huelga de hambre, lo que suponía, según la dirección política, «concienciarlos» y extraerlos de sus inclinaciones individualistas, de su sumisión al estatuto de «parásito» por culpa de la experiencia de sin-papeles. Simplificando, el Comité intentaba negociar con la prefectura para regularizar a los/as sin-papeles cuya situación era seleccionada por la comisión jurídica. Cuando demasiados/as sin-papeles se encontraban con su «caso bloqueado», la dirección política empezaba a dar la palabra a varios sin-papeles «jefes de grupos» durante asambleas públicas. Estos jefes empezaban a pedir una nueva huelga de hambre pero, durante meses, la dirección política impedía que la propuesta fuese sometida a votación y organizaba ocupaciones de edificios públicos, sistemáticamente expulsadas por la policía. Tales ocupaciones servían a la dirección política para determinar el grado de determinación de los/as sin-papeles y elegir los/as que podrían aguantar una huelga de hambre. Después de semanas de acciones, se decidía empezar la huelga y, tras veinte días escondida, la gente elegida salía a la calle y empezaba una guerra abierta con las autoridades. Desde 1996, al menos siete huelgas colectivas ya habían permitido la regularización de más de dos mil sin-papeles. Tal estrategia daba mucho éxito al Comité que reunía, en el año 2007, hasta quinientos/as sin-papeles durante sus manifestaciones semanales. Por razones de mutación y de distancia política con los métodos del Comité, corté con él a principios de la primera huelga que fracasó.

Como se observa aquí, el modelo de la coerción está basado en una división del trabajo militante estricta, no dejando ningún espacio de autonomía a los/as sin-papeles. Además, el modelo se basa en una visibilidad predominante de los hombres, una división sexuada del trabajo y una relegación de las mujeres a tareas conectadas con el campo doméstico. La condición de la participación y de un tratamiento de su caso es la obediencia sin salida porque todo el proceso de movilización y de selección de los/as sin-papeles meritorios está en manos de los aliados (mediante dirección política, portavoz, comisión jurídica). En tal contexto, hay resistencias de los/as sin-papeles pero siempre para criticar las desigualdades de trato entre los orígenes o los sexos (Dunezat, Dominación 414-416), sin que nunca los aliados fuesen criticados por su posición dominante. Lógicamente, la participación de los/as sin-papeles está asociada solamente a la esperanza de papeles, con una rotación muy 
fuerte cada vez que uno/a los obtiene, y su presencia depende del éxito de las acciones. Así, el Comité experimenta una grave crisis numérica desde que las huelgas de hambre fracasan.

\subsection{El Colectivo y el modelo de la autonomía}

Al revés, el Colectivo se presenta como asambleísta, es decir que todo debe organizarse y estar controlado durante las asambleas generales semanales. No hay portavoz ni cualquier otro estatuto formal porque el Colectivo no es una asociación y se presenta como un «colectivo de individuos». No hay cuota, tampoco tarjeta de afiliación, y se suele decir a toda nueva persona que puede participar en la toma de decisiones tan pronto como llega. Tampoco hay comisiones formales de trabajo y, si alguien escribe una octavilla (lo que se hace para cada acción), debe hacer fotocopias para que todas las personas puedan discutir el texto antes de que se distribuya. La rotación de las tareas es un principio establecido y cada vez recordado con el objetivo de favorecer la participación directa y activa de las mujeres y los/as sin-papeles. La toma de decisiones se debe hacer por consenso y se rechaza el voto mayoritario, pero cada participante tiene derecho de veto en cuanto a las decisiones tomadas, lo que puede desembocar en un cambio o su desestimación. Con la práctica establecida de la «asamblea continúa», durante las acciones, los/as participantes tienen derecho a adaptar las decisiones de la asamblea semanal en función de los acontecimientos durante las ocupaciones de los edificios (negociación, amenazas, expulsión).

La entrada ordinaria de los/as sin-papeles en el Colectivo se hace por tres vías principales: invitación de la permanencia jurídica, iniciativa de los/ as sin-papeles después de una acción pública o tras haber visitado el sitio Internet, incitación de antiguos/as sin-papeles cuando la persona se encuentra bloqueada en sus trámites. Se suele insistir sobre el carácter mixto de la lucha, el derecho de los/as sin-papeles a reunirse sin los/as aliados/as dentro del Colectivo, la necesidad de construir una lucha autónoma de sin-papeles, la propuesta de que éstos/as tomen la palabra durante las acciones y con la prensa... Entre los principios de funcionamiento, destacan la ausencia del orden del día y la idea de que cualquiera persona presente pueda hablar de lo que quiera y cuando quiera. Tal práctica fue pensada para favorecer la palabra 
de las personas que no están familiarizadas con las reglas de la militancia dominante. En este modelo de la autonomía, se observa cuánto la militancia de los/as sin-papeles fue pensada por los/as lanzadores como un acto voluntario que debe permanecer voluntario.

En comparación con la fuerte presencia de los/as sin-papeles en el Comité, el fracaso del Colectivo es muy relevante. Simplificando (Dunezat, Herramientas 105-107), se pueden distinguir dos grandes períodos en cuanto a su composición desde su creación. En los años 2002-2009, se organizan sobre todo acciones en relación con el riesgo de expulsión de un/a sin-papeles. Durante días o semanas, se unen los/as sin-papeles y los/as aliados/as hasta que la gente es liberada o regularizada. Cuando lo es, el Colectivo vuelve a su funcionamiento rutinario. En este primer periodo, se suele decir que es un grupo de «franceses» porque la presencia de sin-papeles es casi sistemática pero con fuerte rotación. La agenda de la política migratoria determina el tipo de interseccionalidad que caracteriza la presencia de sin-papeles.

Esto cambia en el año 2010 cuando, durante una acción en contra de las colas de espera en la prefectura, encontramos a un hombre sin-papeles, pastor evangelista congoleño. La llegada del pastor provoca la creación, a nivel local y apoyada materialmente por el Colectivo, de un «Consejo de los migrantes» que agrupa a casi veinte migrantes -en su abrumadora mayoría congoleños/ as- y toma la forma de una asociación con un presidente (el pastor), una reunión semanal y una asamblea general anual (Charasse 21-25). En pocos meses, este Consejo -en concreto el pastor- se convierte en una fuerza más dentro del ámbito local de la solidaridad con los/as sin-papeles. Organiza acciones e impone su voz en las declaraciones públicas. Sobre todo, incita a los/as migrantes del Consejo a asistir más a las asambleas del Colectivo y a ocupar su lugar. En pocos meses, se estabiliza la presencia de un tercio de sin-papeles entre los/as participantes y aparece por primera vez una participación duradera y desconectada del riesgo inminente de expulsión. Criticando el funcionamiento libertario del Colectivo, el pastor exige que «los migrantes» tengan la palabra final en la orientación de las acciones, incluso en la denominación del Colectivo porque quiere acabar con la palabra «degradante» de sin-papeles.

Por primera vez en su historia, el Colectivo tenía una ocasión de ver la dominación de los/as aliados/as suplantada por la de un grupo de sin-papeles, 
pero las prácticas autoritarias del pastor -incluso su sexismo y su homofobia asumidos- legitimaron el rechazo de sus propuestas. Una vez más, el control político de los/as aliados/as desembocó en el rescate del mecanismo central de la dominación: su prescripción del trabajo militante.

\subsection{Las vías negadas de la militancia}

El gran interés del pensamiento feminista negro proviene también de su capacidad para encontrar la militancia donde muchos trabajos académicos no la pueden percibir. Cuando los/as aliados/as piensan que se puede movilizar a los/as sin-papeles, olvidan o no ven que ya están movilizados/as como otros grupos excluidos (Cohen y Dunezat).

Primero, «la supervivencia es una forma de resistencia» (Collins, Pensée 316) y es una experiencia individual y colectiva de los/as sin-papeles, la cual es productora de un «capital vivido» que los/as aliados/as tienen dificultad para percibir y movilizar. Por ejemplo, nunca se organizan las permanencias jurídicas de tal manera que este capital contribuya a la eficacia de la acogida de los/as sin-papeles y permita la participación de ellos/as en las mismas. Sólo el conocimiento jurídico estructura las relaciones de acogida. Si el Colectivo deja lugar algunas veces a la gestión individual de los trámites, cuando una gran manifestación (de aliados/as) o una ocupación (de aliados/as) ya están previstas, se pide a la persona volver a la permanencia jurídica. Se deja así pensar que la militancia no es el lugar de los/as que tienen su capital vivido para legitimar su presencia y el «capital militante» (Matonti y Poupeau 7) de los/as aliados/as recupera sus derechos.

Segundo, los/as aliados/as comparten con las instituciones racistas el sentimiento de que las luchas públicas por el cambio institucional deben tomar una forma peculiar, lo que oculta la variedad de las formas disponibles. Por ejemplo, en sus trámites individuales en la prefectura, los/as sin-papeles multiplican los gestos de resistencia: no salir del mostrador, llorar o gritar, tirarse al suelo y no moverse, huir cuando la policía llega, amenazar con suicidarse incluso tomando pastillas, volver a la prefectura con una barra de acero y romper cristales, inmolarse... Cada vez, tales resistencias -colectivas porque toman formas compartidas- son despolitizadas por los/as aliados/as cuando contestan a la prensa hablando de «actos desesperados». No obstante, tales 
maneras de luchar forman parte de la historia de los grupos excluidos que no consiguen hacerse un sitio en las luchas más formales y legales, como cuando las mujeres negras se negaban a salir de los lugares de la segregación racial o participaban en disturbios urbanos. Sea el Colectivo o el Comité, el hecho de que los/as aliados/as establezcan el trabajo militante genera la incapacidad de imaginar acciones en relación con las formas en apariencia eruptivas de la resistencia.

Tercero, Collins explica que el repliegue por causa de la segregación racial hacia las iglesias, escuelas y organizaciones comunitarias negras constituyó un foco de resistencia de intensidad variable pero continúa (Pensée 48). En el caso de los/as sin-papeles, por lo que me contaron varios/as de ellos/as, el papel del repliegue comunitario es ambivalente porque «las comunidades constituyen importantes focos de reproducción de las relaciones de poder interseccionales como de contestación de éstas» (Collins, Difference 28). En efecto, si consideramos que los/as sin-papeles y los/as aliados/as tienen poca homogeneidad social, la convivencia en la lucha es muy difícil, lo que da mucho éxito a la comunidad. Por ejemplo, en muchas asambleas del Colectivo, las mujeres están sobrerrepresentadas entre los/as aliados/as mientras que los hombres lo están entre los/as sin-papeles, lo que provoca en éstos un replanteamiento de su posición dominante habitual en la comunidad porque son las aliadas las que dirigen ciertas asambleas.

El ejemplo de las iglesias evangelistas, en el caso del Colectivo, es también interesante. Se cuentan localmente más de veinte iglesias que actúan como proveedores de servicios materiales y lugares de concentración de centenares de africanos/as cuando el Colectivo consigue movilizar a diez como máximo. Igualmente, cuando una persona destacada de la comunidad religiosa está detenida, una iglesia puede movilizar en pocas horas a un gran número de migrantes para que sea liberada. Sin embargo, los/as aliados/as ven con mucha sospecha el papel del evangelismo. Cada vez que los/as sin-papeles proponen movilizar a las iglesias, se enfrentan a silencios o protestas por parte de muchas aliadas que no soportan el discurso evangelista sobre las mujeres o la homosexualidad.

Así, poco importa aquí la legitimidad de tales dinámicas, varias dimensiones centrales en la militancia real de los/as sin-papeles no están reconocidas por los/as aliados/as.

Feminismo/s 33, junio 2019, pp. 117-144 


\section{LA LUCHA COMO COMUNIDAD EMANCIPADORA REAL}

Los fracasos no deben esconder las dinámicas emancipadoras. En primer lugar, los movimientos de sin-papeles se inclinan a lograr la justicia social, es decir la regularización de todos/as los/as sin-papeles, la libre circulación e instalación de personas. Tales objetivos nos acercan a problemas prácticos de acceso a la posibilidad de circular e instalarse, lo que nos suma a otros objetivos de justicia social: el derecho al empleo, la democratización del trabajo doméstico, la libertad en la sexualidad, etc. El proyecto político que subyace a la lucha nos acerca a la cuestión de la imbricación de las luchas: no se puede imaginar un mundo sin racismo si se mantiene simultáneamente un orden patriarcal y capitalista. En este sentido, los movimientos estudiados aparecen como verdaderos laboratorios de utopía a nivel ideológico.

Sin embargo, propongo insistir sobre el hecho de que las luchas por el cambio institucional, en tanto que movimientos «con los pobres», constituyen laboratorios de utopía desde dos otros puntos de vista: práctico (5.1) y ético (5.2).

\subsection{El trabajo colectivo}

Al contrario de lo que ocurre en un orden social organizado con los principios de separación cuando no es segregación y de jerarquización, las luchas de los/as sin-papeles se convierten en espacios de convivencia relativa de grupos que casi nunca comparten y hablan, excepto en situaciones estructuradas por los ejes de opresión. Hombres y mujeres; jóvenes y mayores; blancos/ as y negros/as; europeos/as, árabes y africanos/as. El proceso de producción de estas categorías políticas atraviesa también las luchas pero con una forma específica que, casualmente, puede subvertir sus relaciones ordinarias. Me refiero aquí a lo que la lucha propone y, algunas veces, produce en términos de funcionamiento alternativo a los sistemas de dominación.

Por una parte, a pesar de su división, las luchas secretan un «trabajo militante» (Nicourd 13-14) que da sentimiento de utilidad social a los/as sin-papeles cuando el racismo institucional condena a la inactividad. Sobre todo en el Comité porque tiene un local que cuidar y las tareas permiten dinámicas de reconversión de competencias domésticas o profesionales (Cohen y Dunezat 244-258). Además, en el funcionamiento asambleísta, se suele 
discutir todas las tareas militantes con transparencia, lo que permite dar visibilidad al trabajo ejecutivo de los/as dominados/as y compartir el sentimiento de hacer juntos/as, por ejemplo, cuando se ofrece la posibilidad de modificar las octavillas escritas por los/as dominantes. Destaca aquí el hecho de que, en el Colectivo, un trabajo está organizado para escribir octavillas a partir del capital vivido de los/as sin-papeles, lo que desemboca en momentos específicos de escucha de sus experiencias reales. Aunque no controlen la organización del trabajo militante, éstos/as se convierten en artesanos de ocupaciones y de sus reivindicaciones.

Por otra, cuando existe el derecho a hablar en las asambleas, se autoriza una subversión relativa de los tabúes del orden social. Primero, los/as dominados/as aunque son relegados en la división del trabajo militante significan algo para los/as dominantes porque hablan, proponen, participan y se les da un incentivo para que lo hagan. Me refiero aquí a varios momentos colectivos ambivalentes durante los cuales los/as aliados/as dan muestras de «contención» y escuchan con solemnidad, mezclando lástima y admiración, a los/as sin-papeles contando su migración y «el empoderamiento» que revela (Royo et al. 239-240). Segundo, los/as dominantes se encuentran muchas veces acusados de dominar y se les recuerdan sus privilegios, específicamente en el racismo, el sexismo, la sexualidad. Destaca aquí el hecho de que se construyen sororidades entre mujeres aliadas y sin-papeles para criticar la dominación masculina. Igualmente en el Colectivo, y aunque sea durante momentos de sociabilidad entre aliados/as, el feminismo inclusivo sirve de punto de vista para criticar las relaciones de poder entre aliados/as -específicamente los hombres-y los/as sin-papeles. En otras palabras, los/as dominados/as se encuentran en posición de sentirse iguales al compartir la experiencia militante.

Así, a pesar de la división del trabajo militante, se desarrolla un sentimiento de «trabajo colectivo» (Cohen y Dunezat 153), es decir, una forma de apropiación del trabajo de los/as otros/as, sean dominados/as o dominantes, y de identificación con el grupo movilizado, lo que desemboca en una gran solidaridad durante las acciones y frente a las instituciones. En este sentido, las luchas de sin-papeles, bajo diversas formas, pueden aparecer como verdaderos laboratorios de utopía a nivel práctico. 


\subsection{El consenso como dispositivo inclusivo}

Cuando se trata de profundización democrática, la separación entre la deliberación y la participación se superpone con dicotomías simbólicas que estructuran el modelo representativo: calidad/cantidad, élite/pueblo, razonable/ democrático, diálogo/implicación. El problema se centra en cómo podemos «desarrollar una democratización inclusiva, entendida ampliamente como aquella sensible a los agentes que no suelen ser escuchados» (MartínezPalacios y Martínez-García, Miradas 347). Me parece muy importante aquí elegir entre el dispositivo del voto mayoritario y el del consenso.

El voto mayoritario es característico de la democracia representativa y, en el ámbito de los movimientos sociales, tiene consecuencias similares. Específicamente, cuando el tema es muy importante, la acción colectiva se encuentra dividida entre los/as pros y los/as contras, sin olvidar las abstenciones. En el Comité, considerando que sólo la dirección política tenía el poder de decidir los temas, las formulaciones y los momentos de votación, me encontré muchas veces dentro de asambleas muy conflictivas, incluso violentas, porque la decisión adoptada polarizaba al grupo entre tendencias incompatibles. Al respecto, el feminismo negro ofrece una alternativa cuando propone prestar atención a las alianzas, a la diversidad de la militancia y al compromiso teniendo en cuenta el contexto (Collins, Pensée).

En el Colectivo, se valoriza el consenso con derecho de veto de todo/a participante como único modo de decisión. En concreto, significa discutir hasta que la decisión convenga a todos los/as presentes -lo ideal, a pesar de sus límites cuando toma la forma real de un silencio mayoritario y de una actitud pasiva de la gente- lo que supone que todos/as atiendan a todos/as y acepten la idea de que el carácter colectivo de la decisión es más importante que su preferencia individual. Por ejemplo, durante las asambleas, una persona hace una propuesta de acción y, si nadie contesta, se considera como adoptada, en general mediante la declaración de validación por un aliado blanco, profesor, quien tiene una posición dominante en la división del trabajo militante. Si es contestada, comienza la discusión y está establecido que cada uno/a intente encontrar una nueva propuesta consensual. Si no lo conseguimos, es raro, la propuesta es abandonada. En la mayoría de los casos, es el profesor quien 
desempeña el papel de incitar a la palabra crítica, de tener en cuenta las tendencias y de reformular la propuesta hasta el consenso.

No significa el consenso acabar con los conflictos y la dominación sino crear las condiciones para que una decisión sea realmente colectiva, es decir que no sea el resultado de la estrategia individual, voluntaria o no, de un grupo social habilitado, es decir dominante. Nos acerca a la cuestión de una socialización política alternativa. En una lucha mixta logrando la igualdad dentro de un contexto macro-estructural de opresión interseccional, lo más importante será que la decisión colectiva permita la participación de todos/as. Hablo de socialización porque tal funcionamiento supone aprender y sobre todo interiorizar, no tanto, normas y valores sino prácticas entre las cuales destacan las de construir una convivencia continúa y de seguir luchando juntos/as, sin renunciar a sus valores fundamentales individuales (lo que permite el veto). Simplificando, el dispositivo del consenso está interiorizado cuando uno/a acepta el hecho de que su propuesta inicial se ha renovado enteramente sin que sea contraria a lo que le anima a participar en el Colectivo.

Así, más a nivel ético, tal funcionamiento me parece muy importante dentro de luchas que deben construirse teniendo en cuenta la diversidad interseccional de las pertenencias. Usando el consenso, el Colectivo puede garantizar al menos sobre el papel esta diversidad porque no deja al voto mayoritario actuar de tal manera que el grupo movilizado, poco a poco, se homogeneíza (Cohen y Dunezat 273-276).

\section{CONCLUSIONES}

Nos enfrentamos a la fuerza heurística de la noción de comunidad propuesta por Collins para analizar el comportamiento político de los/as sin-papeles. Es evidente que su estatuto se convierte, para ellos/as, en motor de enfrentamiento experiencial con las instituciones opresivas del racismo institucional. Tal dinámica real desemboca en la «comunidad sin-papeles» prescrita por los/ as aliados/as, ya que tal identificación es considerada eficaz para combatir las políticas migratorias. Sin embargo, la experiencia común de carecer de papeles no se convierte en un marco colectivo de vida y de resistencia. Los/ as sin-papeles se identifican más con sus comunidades de origen, dentro de las cuales se reproducen las opresiones interconectadas, lo que conduce a 
los/as aliados/as a rechazar la centralidad de tales comunidades reales en la lucha. Lógicamente, para que el cambio institucional sea posible, destaca la comunidad real de militancia, dirigida por los/as aliados/as. Tal comunidad desigual actúa tanto en el marco práctico, cognitivo como emocional, dentro del cual se experimentan dinámicas de profundización democrática.

De este modo, la comunidad prescrita de los/as sin-papeles aparece superada por la comunidad real de los/as participantes en la lucha porque comparten a la vez el fracaso de hacer realidad una lucha de sin-papeles, el éxito de luchar juntos/as asumiendo sus posiciones contradictorias estructurales y la tentativa constante -desviando la semántica de Crenshaw- de disminuir los efectos de la «interseccionalidad estructural» construyendo una forma de «interseccionalidad política» diaria. Tal comunidad desigual actúa como el marco práctico, cognitivo y emocional, dentro del cual se experimentan dinámicas de profundización democrática.

\section{REFERENCIAS BIBLIOGRÁFICAS}

Aierbe, Peio. «La irrupción de los sin papeles». Mugak 14 (2001): 7-12.

Bourdieu, Pierre. «Espace social et genèse des «classes»». Actes de la recherche en sciences sociales 52-53 (1984): 3-14.

Cahiers du Genre. «Analyse critique et féminismes matérialistes». Hors-série (2016).

Carmichaël, Stokely, y Charles Hamilton. Le Black Power. Pour une politique de libération aux États-Unis. Paris: Payot\&Rivages, 2009.

Charasse, Renaud. «Domination et résistance dans l'action collective en faveur des sans-papiers: une dynamique des rapports sociaux de race». Raison présente 186 (2013): 15-26.

Cohen, Valérie, y Xavier Dunezat. Quand des chômeurs se mobilisent... Rennes: Presses Universitaires de Rennes, 2018.

Collins, Patricia Hill. La pensée féministe noire. Savoir, conscience et politique de l'empowerment. Paris: Éditions du remue-ménage, 2016.

- - "The Difference That Power Makes: Intersecionality and Participatory Democracy». Investigaciones Feministas 8.1 (2017): 19-39.

Cornuau, Frédérique, y Xavier Dunezat. «Faire figure d'immigré-E». Espace, populations, sociétés 3 (2008): 463-481. 
Crenshaw, Kimberlé Williams. «Cartographie des marges: intersectionnalité, politique de l'identité et violences contre les femmes de couleur». Cahiers du Genre 39.2 (2005): 51-82.

Delphy, Christine. L'ennemi principal. Tome 2: Penser le genre. Paris: Syllepse, 2001.

Dunezat, Xavier. «Dominación masculina y feminismo en los movimientos sociales». Política y Sociedad 54.2 (2017): 387-407.

-. «Sexo, raza, clase y etnografía de los movimientos sociales. Herramientas metodológicas para una perspectiva interseccional». Investigaciones Feministas 8.1 (2017): 95-114.

Falquet, Jules. «La règle du jeu. Repenser la co-formation des rapports sociaux de sexe, de classe et de «race» dans la mondialisation néo-libérale». Sexe, race, classe. Pour une épistémologie de la domination. Ed. Elsa Dorlin. Paris: PUF, 2009. 71-90.

Fillieule, Olivier, y Patricia Roux, eds. Le sexe du militantisme. Paris: Presses de Science Po, 2009.

Galerand, Elsa, y Danièle Kergoat. «Consubstantialité vs intersectionnalité? À propos de l'imbrication des rapports sociaux». Nouvelles pratiques sociales 26.2 (2015): 44-61.

Geisser, Vincent, ed. «Un racisme institutionnel en France?». Migrations Société 28.163 (2016).

Jabardo Velasco, Mercedes, y Beatriz Ródenas Cerezo. «Más allá de las dicotomías. Un análisis de la actividad del trenzado en la diáspora senegalesa desde el feminismo negro». Revista Española de Sociología 26.3 (2017): 373-384.

Jaegermann, Zuzanna. «El estatus «irregular» de los/as inmigrantes como una construcción socio-política». Itinerarios 13 (2011): 209-224.

Juteau, Danielle. «Un paradigme féministe matérialiste de l'intersectionnalité». Cahiers du Genre, hors-série (2016): 129-149.

Kergoat, Danièle. Se battre, disent-elles... Paris: La Dispute, 2012.

Krueger, Laura. «El movimiento de los sin-papeles en Francia en los años noventa y sus reflejos en España». Scripta Nova 94.25 (2001). 31 diciembre 2018.

Le Borgne de Boisriou, Valentine. «Una indagación sobre la subjetivación: el caso de los «sin-papeles» en Francia». Movimientos sociales y subjetivaciones políticas. Eds. Anders Fjeld, Laura Quintana y Étienne Tassin. Iconos. Revista de Ciencias Sociales 58 (2017): 183-200. 
Martínez García, Patricia. «Democratizando el mar con perspectiva de género. El proceso de profesionalización de las mariscadoras a pie en Galicia». Política y Sociedad 54.2 (2017): 377-398.

Martínez Palacios, Jone, y Patricia Martínez García. «Justicia social, interseccionalidad y profundización democrática. Presentación». Investigaciones Feministas 8.1 (2017): 9-17.

Martínez Palacios, Jone, y Patricia Martínez García. «Miradas feministas sobre la profundización democrática. Presentación». Política y Sociedad 54.2 (2017): 345-351.

Mathieu, Lilian. Mobilisations de prostituées. Paris: Belin, 2001.

Matonti, Frédérique, y Franck Poupeau. «Le capital militant. Essai de définition». Actes de la recherche en sciences sociales 155 (2004): 5-11.

McCarthy, John D., y Mayer Zald. «Resource Mobilization and Social Movements: a Partial Theory». American Journal of Sociology, 82 (1977): 1212-1241.

Nicourd, Sandrine, ed. Le travail militant. Rennes: PUR, 2009.

Péchu, Cécile. Droit Au Logement, genèse et sociologie d'une mobilisation. Paris: Dalloz, 2006.

Pedreño, Andrés, y Manuel Hernández, eds. La condición inmigrante. Exploración e investigaciones desde la Región de Murcia. Murcia: Universidad de Murcia, 2005.

Royo, Raquel, María Silvestre, Lia González, Estibaliz Linares, y Maialen Suárez. «Mujeres migrantes tejiendo democracia y sororidad desde el asociacionismo. Una aproximación cualitativa e interseccional». Investigaciones Feministas 8.1 (2017): 223-243.

Santi Pereyra, Silvana. «Sobre «ilegales», «irregulares»y «sin papeles». La lucha por la regularización documentaria de los inmigrantes extracomunitarios en España». Estudios Políticos 53 (2018). 31 de diciembre de 2018.

Siméant, Johanna. La cause des sans-papiers. Paris: Presses de Sciences Po, 1998. Suárez Navaz, Liliana, Ángela Moreno García, y Raquel Macià Pareja, eds. Las luchas de los sin papeles y la extensión de la ciudadanía. Perspectivas críticas desde Europa y Estados Unidos. Madrid: Traficantes de Sueños, 2007.

Varela Huerta, Amarela. « «Luchas migrantes»: un nuevo campo de estudio para la sociología de los disensos». Andamios 12.28 (2015): 145-170.

Varela Huerta, Amarela. Por el derecho a permanecer y a pertenecer. Una sociología de las luchas de los migrantes. Madrid: Traficantes de Sueños, 2013. 